\title{
A EVOLUÇÃO DO ESPAÇO AGRÁRIO FLUMINENSE
}

\author{
Paulo Roberto R. Alentejano* \\ Universidade do Estado do Rio de Janeiro
}

O estado do Rio de Janeiro é inegavelmente um espaço metropolizado. Ao longo do século XX, o enorme crescimento da cidade do Rio de Janeiro e o crescente esvaziamento econômico do interior do estado ${ }^{1}$ levaram a uma enorme polarização do espaço fluminense, absolutamente dependente da capital estadual. Vale dizer que a influência da capital fluminense espraia-se para além dos próprios limites estaduais, estendendose para áreas dos estados de Minas Gerais e Espírito Santo, porém, nos marcos deste trabalho nos limitaremos às fronteiras estaduais, afinal, o Estado, nas suas diversas instâncias, é elemento de central importância para refletirmos acerca dos processos de ordenamento territorial. ${ }^{2}$

Dentre os principais agentes organizadores do espaço fluminense ao longo deste século, destacam-se o capital industrial e o capital imobiliário. O primeiro foi o

\footnotetext{
* Geógrafo, Doutor em Desenvolvimento, Sociedade e Agricultura e Professor do DGeo/FFP/UERJ.

${ }^{1}$ Vale lembrar que até 1960 a cidade do Rio de Janeiro tinha status de Distrito Federal, por abrigar a capital do país, enquanto que o estado do Rio de Janeiro, tinha Niterói como capital. Entre 1960 e 1975, passaram a coexistir dois Estados, o da Guanabara, no antigo território do Distrito Federal, um estado de um só município e uma só cidade, e o do Rio de Janeiro, mantendo suas antigas características. A partir de 1975, os dois estados foram fundidos num único estado, denominado Rio de Janeiro, passando a capital deste a ser a cidade do Rio de Janeiro. Os impactos da fusão sobre a realidade estadual são até hoje alvo de controvérsia e diversas propostas de desfusão já foram feitas ao longo deste período, tanto por políticos da capital que sustentam que a cidade do Rio de Janeiro foi prejudicada, como por políticos do interior que julgam que foi esta a região que mais perdeu com a fusão.

${ }^{2}$ Apesar da crescente tendência a se negar a importância do Estado no atual contexto de globalização, consideramos que há um exagero nestas afirmações e o Estado continua tendo importante papel na organização espaço-territorial, inclusive ao conceder incentivos cada vez maiores ao capital em seu crescente processo de territorialização-desterritorializaçãoreterritorialização, como fica patente na «guerra fiscal» em andamento no Brasil (ver a este respeito, entre outros, SANTOS e SILVEIRA, 2001).
} 
principal responsável pelo impulso inicial do processo de metropolização. Já o segundo foi o principal agente da crescente subordinação do capital agrário no interior do estado, assim como da expulsão maciça do campesinato do campo, exceção feita às regiões Norte e Noroeste, onde o agente central da expulsão dos trabalhadores do campo foi o próprio capital agrário, em suas metamorfoses.

Tais fatos refletem-se em alguns dados estatísticos que ajudam a compreender as características centrais da organização do espaço fluminense: $96 \%$ da população reside em áreas urbanas; a região metropolitana concentra $75 \%$ da população, $80 \%$ do valor da produção industrial, $85 \%$ da arrecadação do Imposto sobre Circulação de Mercadorias e Serviços (ICMS), sendo que $70 \%$ deste imposto é arrecadado na capital.

Por outro lado, a participação do setor agrícola no Produto Interno Bruto (PIB) fluminense é inferior a $2 \%$ (CIDE, 2001). ${ }^{3} \mathrm{O}$ processo de desruralização, entendido como esvaziamento econômico e demográfico e perda de peso político e cultural, foi tão intenso no estado que entre 1940 e 2000 , a população rural decresceu de 1.400 .000 pessoas (38,8\% do total em 1950) para 570.000 pessoas (4\% do total em 1996), conforme a Tabela 1, abaixo.

\section{Tabela 1 - População residente por local de domicílio e taxa de urbanização Rio de Janeiro - 1940/2001}

\begin{tabular}{rrrrc}
\hline Ano & \multicolumn{1}{c}{ Total } & Urbana & \multicolumn{1}{c}{ Rural } & Taxa de Urbanização (\%) \\
\hline 1940 & 3.611 .998 & 2.212 .211 & 1.399 .787 & 61,2 \\
1950 & 4.674 .645 & 3.392 .591 & 1.282 .054 & 72,6 \\
1960 & 6.649 .646 & 5.252 .631 & 1.397 .015 & 79,0 \\
1970 & 8.994 .802 & 7.906 .146 & 1.088 .656 & 87,9 \\
1980 & 11.291 .520 & 10.368 .191 & 923.329 & 91,8 \\
1991 & 12.807 .706 & 12.199 .641 & 608.065 & 95,3 \\
1996 & 13.406 .379 & 12.806 .488 & 599.891 & 95,5 \\
2000 & 14.367 .083 & 13.798 .096 & 568.897 & 96,0 \\
\hline
\end{tabular}

Fonte: IBGE, Censos Demográficos.

Entretanto, se a metropolização e a deșruralização são uma marca dominante na organização do espaço fluminense, isso não elimina as contradições presentes neste

\footnotetext{
${ }^{3}$ Apesar de irrisório em termos proporcionais, o PIB agrícola estadual não chega a ser desprezível em termos absolutos, atingindo 1,17 bilhões, o que equivale ao do estado vizinho do Espírito Santo, onde este equivale a $45 \%$ do PIB estadual (IBGE, 2001).
} 
processo. Dentre estas inúmeras contradições, interessa-nos especialmente a resistência dos trabalhadores rurais ao avanço do capital especulativo, que é a marca dos conflitos fundiários no estado, inclusive na região metropolitana.

Assim, ao longo deste artigo - onde buscaremos analisar as formas principais de ordenamento do território que marcam o espaço fluminense, bem como as regionalizações daí surgidas, tomando o século XX como parâmetro - estaremos permanentemente preocupados com a evolução destes conflitos.

Apesar de não ignorarmos a importância dos processos ocorridos ao longo dos séculos anteriores para a definição do perfil da ocupação do espaço fluminense, nos concentraremos no século $\mathrm{XX}$, por considerar que foi ao longo deste que ocorreram as transformações mais substanciais e importantes, do ponto de vista da questão agrária e do ordenamento do território.

Buscaremos destacar a configuração de novos recortes regionais a partir das transformações operadas no meio rural, resultantes da sua própria dinâmica, ou das influências dos processos de urbanização e metropolização. A periodização apresentada a seguir tem como critérios norteadores precisamente as mudanças na dinâmica sócioespacial fluminense que nos permitem identificar novos recortes espaciais e inflexões na relação entre o rural e o urbano no Rio de Janeiro.

\section{A GEOGRAFIA DO RIO DE JANEIRO NO INÍCIO DO SÉCULO XX}

Até o início do século XX, a organização do espaço fluminense era hegemonizada pelo capital agrário e pelo capital mercantil. Entretanto, as diferentes condições ambientais existentes no Rio de Janeiro - aliás a diversidade ambiental é um elemento fundamental na definição dos diferentes projetos de ordenamento do território no Rio de Janeiro, seja no passado, seja no presente - concorriam para a existência de diferentes formas de ordenamento territorial.

Nesse período, podemos reconhecer, basicamente, quatro regiões no estado, produto das formas diferenciadas de ordenamento do território: (1) a região do Vale do Paraíba, dominada pela oligarquia cafeeira e marcada pela ampla destruição da Mata Atlântica produzida pelo avanço extensivo e degradador da cultura do café, num ambiente onde as condições edafo-climáticas originais eram extremamente favoráveis ${ }^{4} ;(2)$ a região das baixadas situadas a leste da região da Baixada da Guanabara, estendendo-se até os limites com o Espírito Santo, ao norte, dominada pela oligarquia canavieira e marcada pela existência de inúmeros engenhos de açúcar em meio aos amplos canaviais que se estendiam pelas baixadas aluviais e tabuleiros litorâneos; (3) a região da Baixada da

\footnotetext{
${ }^{4}$ Solos de boa profundidade e fertilidade, clima tropical de altitude, ou seja, combinando expressiva insolação com uma temperatura amena e praticamente livre de geadas.
} 
Guanabara, dominada pelo capital comercial que organizava a agroexportação e a redistribuição interna dos bens e da riqueza, a partir do controle sobre a vasta área navegável da baía e rios que nela desembocavam; (4) uma vasta região cujo elemento de unidade é a topografia acidentada, estendendo-se do litoral sul até o noroeste do estado, passando pela área da Serra dos Órgãos, a qual, por não ser reivindicada por nenhuma fração expressiva do capital, mantinha-se como área de fronteira e como tal, de reprodução do campesinato, dentre eles, antigos escravos recém libertados e imigrantes (principalmente alemães e suíços).

Percebe-se, portanto, que as frações do capital agrário e comercial, organizavam o espaço a partir da combinação de seus interesses com as particularidades ambientais existentes no estado, onde estas desempenhavam importante papel na definição das formas de ordenamento do território.

\section{AS PRIMEIRAS DÉCADAS DO SÉCULO: O IMPULSO INICIAL DA METROPOLIZAÇÃO E DA DESRURALIZAÇÃO}

A partir das primeiras décadas do século XX, tal configuração regional será profundamente alterada, com a decadência da oligarquia cafeeira e a ascensão da burguesia industrial. Com isto, duas transformações que serão centrais ao longo do século XX e, como vimos anteriormente, podem ser definidas como as marcas da organização do espaço fluminense, se delineiam: o desenvolvimento da metropolização e o início da desruralização do estado.

Neste novo contexto, redefinem-se formas de uso dos recursos naturais e ordenamento territorial. No período que vai até os anos 1940, das quatro regiões descritas anteriormente, duas sofrem expressivas mudanças - o Vale do Paraíba e a Baixada da Guanabara - sem contudo redefinirem expressivamente seus contornos; uma se fragmenta - a região caracterizada anteriormente como de fronteira; e apenas uma mantém suas características básicas - a das Baixadas Leste e Norte.

O Vale do Paraíba é a região mais impactada com as transformações ocorridas no período, sofrendo um brutal esvaziamento econômico e demográfico. A decadência da cafeicultura, provocada pela degradação dos solos que reduziu drasticamente a produtividade, tornou a região incapaz de concorrer com outras áreas produtoras, como o oeste paulista. Esta decadência que já vinha se delineando desde fins do século passado, no rastro da crise da escravidão, torna-se arrasadora nas primeiras décadas deste século. Com isso, os cafezais da região foram sendo paulatinamente abandonados e as cidades da região, até então importantes centros comerciais, foram sofrendo esvaziamento, uma vez que a cafeicultura - atividade rentável e que empregava significativa quantidade de trabalhadores - foi substituída pela pecuária, com seu caráter extensivo e poupador de mãode-obra (GALVÃO, 1986).

Assim, observa-se que não há propriamente uma mudança no que se refere ao tipo 
de capital dominante na região, que continua sendo basicamente o agrário, mas há uma profunda mudança de qualidade neste processo.

Ainda hoje, apesar do desenvolvimento recente de outras atividades, principalmente o turismo, é possível observar em algumas das cidades da região - como Valença e Vassouras - marcas da decadência provocada pela crise do café.

Outra região que sofreu profundas alterações foi a da Baixada da Guanabara que passou de hegemonizada pelo capital comercial para o domínio do capital industrial. A crescente industrialização da cidade do Rio de Janeiro, já nas primeiras décadas do século XX - embora decrescente em relação a São Paulo, no que se refere à participação na economia nacional -, levou a região a aumentar sua influência no âmbito estadual.

No que tange à sua organização interna, a região passa a estar cada vez mais voltada para uma dinâmica endógena, diferentemente do que ocorria antes, onde era a relação de agroexportação a determinante das formas de organização espacial, redundando num ordenamento do território que privilegiava a ligação com o exterior, dando à atividade portuária papel central na estruturação do espaço urbano da região. No novo contexto, o eixo desloca-se crescentemente para as vias de circulação terrestres que integram a região, produzindo uma interiorização da economia regional.

É preciso destacar que do século XVIII até o princípio do XX a cidade do Rio atuou como pólo dinamizador do setor rural, pois o mercado urbano fomentava a ampliação da produção para seu abastecimento, porém, a partir dos primeiros anos do século $\mathrm{XX}$ o efeito passou a ser contrário, com a valorização urbana das terras concorrendo com o uso agrícola destas.

O processo de valorização das terras associado à expansão do grande Rio tem tido papel muito significativo nas transformações que se vêm operando no meio rural fluminense... (BRITO \& INNOCENCIO, 1988: p. 115).

No que se refere à antiga região de fronteira que se estendia do litoral sul ao noroeste do estado, ocorre uma fragmentação crescente, particularmente com a transferência de parte da produção cafeeira para o Noroeste, que passa a se configurar como novo pólo de domínio da oligarquia agrária, ao passo que o litoral sul permanece como a mais típica área de fronteira e a região serrana ganha importância do ponto de vista do capital comercial.

Em função das características edafo-climáticas semelhantes às do Vale do Paraíba embora um pouco mais seca e quente - a região Noroeste individualiza-se crescentemente, por se transformar em refúgio do capital cafeeiro no Rio de Janeiro.

Por sua vez, a região Serrana ganha importância crescente como área de reprodução do capital comercial, uma vez que a região passa a desempenhar dois papéis fundamentais no âmbito estadual: (1) abastecimento alimentício, uma vez que, como área de 
significativa presença de pequenos produtores, torna-se importante para o abastecimento da região metropolitana do Rio de Janeiro, mas é a intermediação comercial que controla este processo, em detrimento dos produtores; (2) elo de ligação com outras regiões do país, uma vez que duas das principais ligações rodoviárias com outros estados e regiões do país cruzam a região, dando margem ao surgimento de um conjunto de atividades de apoio à circulação de mercadorias e pessoas.

Por fim, cabe dizer que a região das Baixadas Leste e Norte permanece basicamente como área de domínio da burguesia canavieira, embora note-se o desenvolvimento nas franjas da região metropolitana de outras atividades produtivas, com a pecuária leiteira $\mathrm{e}$ a citricultura, porém, sem representar alterações expressivas no ordenamento do território.

\section{3 - $O$ IMPULSO DECISIVO DA METROPOLIZAÇÃO: O PERÍODO 1940-1964}

Se nas primeiras décadas do século, o início do processo de industrialização gera o primeiro impulso à metropolização do espaço fluminense, é entre os anos 1940 e 1964 que esta é acelerada e se consolida, produzindo, em sua esteira, a desruralização, embora, já aqui verifiquemos os primeiros movimentos de resistência dos trabalhadores rurais a esse processo.

Vale lembrar que o período em questão é o de maior crescimento demográfico no Estado, como pode ser observado na Tabela 2, abaixo.

Tabela 2 - Taxa média geométrica de crescimento anual da população Rio de Janeiro - 1940/2001

\begin{tabular}{lcccccc}
\hline Período & $1940 / 1950$ & $1950 / 1960$ & $1960 / 1970$ & $1970 / 1980$ & $1980 / 1991$ & $1991 / 2000$ \\
\hline Taxa & 2,61 & 3,68 & 2,97 & 2,30 & 1,15 & 1,28 \\
\hline
\end{tabular}

Fonte: IBGE, Censos Demográficos.

Tal processo acelerou as mudanças na configuração regional do espaço fluminense, através da formulação de novos projetos de ordenamento territorial. As principais transformações nesse período se deram na Região da Baixada da Guanabara, no Vale do Paraíba, na Região Serrana e no Noroeste, permanecendo as áreas do Litoral Sul e das Baixadas Leste e Norte com poucas transformações. Como podemos observar pelos dados da Tabela 3, abaixo, a única das atuais regiões que sofreu esvaziamento populacional no período foi a Região Noroeste, tendo havido em todas as demais crescimento demográfico, embora em ritmos diferenciados e somente na Metropolitana e no Vale do Paraíba um crescimento superior à média estadual. No caso da Baixada da Guanabara, no rastro da expansão industrial, populacional e urbana, tem-se um enor- 
me crescimento da especulação imobiliária, com a tentativa de incorporar cada vez mais áreas ao tecido urbano. ${ }^{6}$

Tabela 3 - População residente e taxa de crescimento, segundo as regiões de governo Rio de Janeiro - 1940/1970

\begin{tabular}{lrrr}
\hline & \multicolumn{3}{c}{ População residente e Taxa de Crescimento } \\
\hline \multicolumn{1}{c}{ Regiões de Governo } & \multicolumn{1}{c}{1940} & \multicolumn{1}{c}{1970} & Crescimento 1940/ 1970 (\%) \\
\cline { 2 - 4 } Estado & 3.611 .998 & 8.994 .802 & 149 \\
Região Metropolitana & 2.231 .567 & 6.891 .521 & 209 \\
Região Noroeste Fluminense & 305.066 & 245.561 & -20 \\
Região Norte Fluminense & 344.053 & 471.038 & 37 \\
Região Serrana & 285.646 & 467.159 & 64 \\
Região das Baixadas Litorâneas & 136.387 & 238.725 & 75 \\
Região do Médio Paraíba & 159.496 & 446.835 & 46 \\
Região Centro-Sul Fluminense & 121.567 & 177.753 & 99 \\
Região da Baía da Ilha Grande & 28.256 & 56.210 & \\
\hline
\end{tabular}

Fonte: IBGE, Censos Demográficos

Este processo provocará profundos conflitos, resultantes, na realidade, do confronto de diferentes projetos territoriais, a saber, o do capital especulativo e o dos trabalhadores rurais.

O ponto de partida deste conflito é a intervenção governamental, realizada nos anos 1930/40, voltada para o saneamento da Baixada da Guanabara, através da canalização e dragagem dos rios que cortam a área. $\mathrm{O}$ objetivo inicialmente declarado desta intervenção era o de viabilizar a implantação de colônias de pequenos produtores agrícolas, com o intuito de abastecer a crescente população da capital federal. De fato, alguns núcleos coloniais foram criados no período, como os da Fazenda Nacional e Santa Alice.

Entretanto, rapidamente, os interesses dos especuladores se sobrepõem e uma série de processos de grilagem se verificam em toda a área da Baixada, dando origem a conflitos intensos pela posse da terra. Isto porque, além dos agricultores assentados nos núcleos coloniais, uma grande quantidade de posseiros dirige-se para a área, atraídos pela possibilidade de se instalar numa área com razoável infra-estrutura e próxima a um mercado consumidor crescente e de alto poder aquisitivo, se comparado à média nacional.

\footnotetext{
${ }^{5}$ No período entre 1950 e 1970 , os municípios da Baixada tiveram crescimento de $340 \%$ na sua população, enquanto que a cidade do Rio de Janeiro teve sua população ampliada em $80 \%$.
} 
Essa afluência de trabalhadores rurais para a Baixada se opõe, portanto, diretamente ao interesse do capital especulativo, de transformar a área em extensão do tecido urbano da capital, via loteamento das antigas áreas rurais. Vale dizer que este processo representa uma revalorização da Baixada, uma vez que esta área fora um importante núcleo de produção agrícola, principalmente de cana e laranja, que se desvaloriza pela multiplicação dos problemas de saneamento acima citados. ${ }^{6}$

Assim, o que a intervenção governamental produz na área é a redefinição do projeto dos capitalistas, uma vez que, antes, esta área era apropriada pelos setores ligados ao capital agrário e, agora, passa a ser objeto de interesse do capital imobiliário. De uma forma ou de outra, estamos diante da tentativa dos capitalistas de realizar a renda da terra, contrapondo-se ao interesse dos trabalhadores rurais de se apropriar da área para viabilizar uma reprodução o mais independente possível do capital.

Os conflitos que ocorrem na Baixada tomaram vulto inesperado, em função da proximidade com a capital federal, redundando num profundo processo de disputa política em torno do controle deste movimento de luta pela terra, marcado por ocupações de terra, choques armados entre posseiros e jagunços, manifestações dos trabalhadores na então capital estadual - Niterói - e, inclusive, desapropriações de terra.

Com o Golpe de 1964 houve intensa perseguição dos trabalhadores, seguida da anulação das desapropriações e a devolução das áreas para proprietários e grileiros, sob o argumento da "vocação urbana» das áreas, consideradas frente natural de expansão do tecido urbano, o que mais adiante veremos não ter se dado integralmente.

No caso do Vale do Paraíba, observou-se uma expressiva transformação regional, com a criação de importantes pólos industriais no eixo da Via Dutra - construída no período -, o que significou uma dupla mudança no ordenamento territorial regional, pois, de um lado, mudou o tipo de atividade predominante, e de outro, mudou o eixo de desenvolvimento.

O predomínio do capital agrário, absoluto até o princípio do século e decadente, mas ainda dominante, nas primeiras décadas, é substituído pela prevalência do capital industrial, sendo importante destacar a importância da participação estatal neste processo, uma vez que o impulso inicial foi dado pela instalação da Companhia Siderúrgica Nacional (CSN), em Volta Redonda - até então uma localidade de Barra Mansa - , no princípio dos anos 1940.

A partir da instalação da CSN, o eixo que vai de Barra Mansa a Resende torna-se crescentemente industrializado, com destaque para a indústria de base, principalmente os setores siderúrgico, metalúrgico e químico-farmacêutico. Por outro lado, as antigas cidades mais importantes da região, como Vassouras e Valença, principais centros na época do café, perdem crescentemente importância no âmbito regional, por estarem mais afastadas deste eixo fundamental de desenvolvimento que passa a ser a área cortada pela rodovia Presidente Dutra.

\footnotetext{
${ }^{6}$ Ver a esse respeito ALENTEJANO, 1997.
} 
Em termos regionais, a oligarquia agrária que ainda predomina nestes antigos centros cafeeiros perde espaço para a ascendente burguesia industrial do novo eixo, profundamente articulada à burguesia metropolitana. Entretanto, há um ponto em comum entre os processos em curso nesta região ao longo de todo este século, que é a desruralização crescente deste espaço.

$\mathrm{Na}$ região Serrana, inicia-se um processo que marcará o ordenamento territorial desta no final do século: o desenvolvimento da atividade turística. A região, como vimos anteriormente, estivera à margem de um projeto territorial da burguesia agrária, e, como tal, pode se manter como área de expansão da pequena produção de alimentos. A partir dos anos 1940, a região se transformará, paulatinamente, em área de expansão turística, favorecida pela proximidade com a capital e as condições ambientais, como o clima ameno e a preservação de boa parte da Mata Atlântica e a construção de rodovias que a cruzam, como a Rio - Belo Horizonte e a Rio - Bahia.

Assim, a região passa a estar crescentemente incorporada à dinâmica metropolitana e afirma-se cada vez mais um ordenamento territorial calcado nos interesses do capital imobiliário que avança sobre as terras até então ocupadas por pequenos produtores, transformando-as em locais de veraneio e segunda moradia para a burguesia metropolitana, o que resulta, também na região, no avanço da desruralização. Isto não significa, entretanto, o fim da produção agrícola na região, a qual permanece sendo importante, principalmente no que diz respeito à oferta de hortigranjeiros para a capital, produzidas pelos pequenos agricultores que se reproduzem nas áreas mais ermas e desvalorizadas.

Também o Noroeste sofreu transformações expressivas no período. Esta região, que se individualizara nas primeiras décadas do século, ao ser transformada em opção de reprodução da burguesia cafeeira estadual, no período 1940/1964, viveu uma forte crise, com a decadência da cafeicultura. A reprodução na região da mesma dinâmica produtiva que arrasara o Vale do Paraíba, gerou o mesmo esvaziamento econômico e populacional que afetara aquela região no princípio do século. Tal fato não constitui surpresa, pois ambas possuem um ambiente bastante semelhante, marcado pelo relevo acidentado típico do domínio dos mares de morros e o clima tropical de altitude, com sua forte sazonalidade de chuvas, em geral de caráter torrencial. Estas condições, associadas a uma forma de plantio do café em fileiras, morro abaixo, favorecem a erosão, determinante para a queda de fertilidade dos solos e com esta a crescente dificuldade de manter a produção.

Esta crise se traduziu num processo intenso de desruralização, a partir da erradicação dos cafezais e sua substituição pela pecuáriả extensiva, processo que também já se verificara anteriormente no Vale do Paraíba, permitindo-nos dizer que o Noroeste reproduz com algumas décadas de atraso a trajetória do Vale do Paraíba. Ao esvaziamento demográfico e econômico somou-se a crescente marginalização da região no contexto estadual.

Assim como no período anterior, as regiões do Litoral Sul e das Baixadas Leste e Norte mantém-se sem grandes transformações, embora seja possível identificar as primei- 
ras marcas do processo que irá diferenciar as Baixadas Leste e Norte após os anos 1960. Isto está relacionado com o início do desenvolvimento da atividade turística na área de Cabo Frio, Araruama, etc. Porém, até os anos 1960, este processo é embrionário e não permite ainda que diferenciemos as duas áreas que continuam a ser basicamente agrícolas, dominadas pela oligarquia açucareira e, secundariamente setores citricultores, salineiros e pecuaristas.

Percebe-se assim que as marcas do período 1940/1964 são a metropolização e a desruralização, além da diversificação de processos de territorialização do capital, com mais um avanço na perda de influência do capital agrário no estado.

\section{OS ANOS 1964/1980 E O AUGE DA DESRURALIZAÇÃO}

Se os anos 1940/1964 têm como marca fundamental a metropolização, o período 1964/1980 é caracterizado, fundamentalmente, pela desruralização que, como vimos, vinha se desenvolvendo desde o princípio do século, mas que avança substancialmente neste período. Este avanço está diretamente relacionado a três processos: as mudanças estruturais na atividade canavieira; a enorme expansão da atividade turística e com ela da especulação imobiliária; a desarticulação da resistência dos trabalhadores rurais pela repressão militar, o que eliminou uma das poucas forças contrárias ao processo dominante de urbanização/metropolização.

Como demonstra a Tabela 4, abaixo, há uma tendência generalizada de redução do ritmo de crescimento demográfico a partir dos anos 1970, exceção feita às regiões Norte Fluminense, das Baixadas Litorâneas e da Baía da Ilha Grande.

Tabela 4 - População residente e taxa de crescimento, segundo as regiões de governo Rio de Janeiro - 1940/1970/2000

\begin{tabular}{lrrrrr}
\hline & \multicolumn{5}{c}{ População residente e Taxa de Crescimento } \\
\cline { 2 - 6 } \multicolumn{1}{c}{ Regiões de Governo } & 1940 & 1970 & $\begin{array}{r}\text { Crescimento } \\
1940 / 1970(\%)\end{array}$ & 2000 & $\begin{array}{r}\text { Crescimento } \\
1970 / 2000\end{array}$ \\
\cline { 2 - 6 } & & & & & \\
Estado & 3.611 .998 & 8.994 .802 & 149 & 14.367 .083 & 60 \\
Região Metropolitana & 2.231 .567 & 6.891 .521 & 209 & 10.872 .768 & 58 \\
Região Noroeste Fluminense & 305.066 & 245.561 & -20 & 297.512 & 21 \\
Região Norte Fluminense & 344.053 & 471.038 & 37 & 696.988 & 48 \\
Região Serrana & 285.646 & 467.159 & 64 & 751.428 & 61 \\
Região das Baixadas Litorâneas & 136.387 & 238.725 & 75 & 560.298 & 135 \\
Região do Médio Paraíba & 159.496 & 446.835 & 180 & 784.813 & 76 \\
Região Centro-Sul Fluminense & 121.567 & 177.753 & 46 & 254.575 & 43 \\
Região da Baía da Ilha Grande & 28.256 & 56.210 & 99 & 148.701 & 165 \\
\hline
\end{tabular}

Fonte: IBGE, Censos Demográficos. 
Mais uma vez, como vimos no caso das transformações na região da Baixada da Guanabara e no Vale do Paraíba, a ação estatal é fundamental para a promoção das mudanças do período. De um lado, os incentivos à modernização da agricultura e, em especial, os incentivos para a produção do álcool, resultaram numa profunda alteração das relações de produção e trabalho na principal área canavieira do estado, a Baixada Campista. De outro, a construção da BR-101, cortando o Litoral Sul e a área das Baixadas Leste e Norte, incentivou significativamente o avanço do turismo e com este a especulação imobiliária.

No dizer de Brito e Innocencio:

$O$ processo de penetração capitalista nas áreas rurais fluminenses tem sido freqüentemente acompanhado pelo processo de concentração fundiária, quer através da aglutinação de áreas de posses, como vem ocorrendo no litoral sul, quer através da aglutinação de propriedades menores ou do arrendamento de extensas áreas para aproveitamento agropecuário, como se tem verificado no vale do São João. (BRITO e INNOCENCIO, 1988:116/117).

Desta forma, a região do Litoral Sul, que até então caracterizava-se por ser uma área de fronteira, distinguindo-se das demais pela inexistência de um projeto efetivo de territorialização do capital - o que permitia que fosse uma área de reprodução de descendentes de indígenas e escravos, além de posseiros - passa a ser alvo do capital imobiliário.

A valorização da área está ligada à imensa beleza natural de suas inúmeras ilhas e praias, associado ao elevado grau de preservação da Mata Atlântica na região. $\mathrm{O}$ acesso facilitado à área pela abertura da rodovia BR-101, conhecida neste trecho como Rio-Santos, desencadeou a corrida dos especuladores, desenvolvendo um intenso processo de grilagem, transformando-a no principal palco de conflitos pela terra, marcado pela tentativa de resistência das populações tradicionais locais, as quais, entretanto, pouco puderam fazer diante do poderio político e econômico dos especuladores. A resistência torna-se ainda mais difícil, na medida em que tais populações - caiçaras e descendentes de escravos - são em geral analfabetas, viveram isoladas durante muito tempo e desconhecem inclusive seus direitos e a legislação.

Processo semelhante ocorreu nas Baixadas Leste, região hoje denominada Baixadas Litorâneas, mas que como vimos, não se diferenciava significativamente da Baixada Campista, até então. Esta passa a ser alvo crescente da atuação do capital especulativo, em função do enorme crescimento do turismo nesta área, facilitado pelo acesso mais rápido garantido pela construção da BR-101. As condições ambientais da região, a de menor índice pluviométrico do estado - daí ser conhecida também como Costa do Sol e de maior quantidade de dias ensolarados - dados os ventos fortes e constantes que antes justificavam a presença nesta da atividade salineira - favoreceram sobremaneira 
a expansão do turismo, num contexto de valorização crescente da praia como local de lazer. Além disso, na faixa interiorana, as obras de drenagem e canalização do rio São João valorizaram as terras, atraindo proprietários rentistas que passaram a arrendá-las terras para uso agropecuário.

Assim, tanto no caso da região do Litoral Sul, como no das Baixadas Litorâneas, vemos o avanço do duplo processo de metropolização e desruralização: metropolização porque aumenta a dependência e a vinculação destas áreas com a capital; desruralização porque os trabalhadores rurais são expulsos do campo e o projeto de ordenamento territorial vincula-se aos interesses do capital especulativo imobiliário ligado ao turismo.

Já na região da Baixada Campista, onde não se verificou tamanho desenvolvimento do turismo, pela existência de menos atrações e a maior distância em relação à capital, o que se deu foi uma profunda reestruturação produtiva. A partir de incentivos governamentais propiciados pelo Programa de Apoio à Agroindústria Açucareira e pelo Programa Nacional do Álcool (PRÓ-ÁLCOOL) a produção de cana na região sofre profundas alterações, seja com a concentração crescente do capital, seja com a radical alteração das relações de trabalho. ${ }^{7}$

No caso das relações de trabalho, a marca fundamental é a expulsão dos trabalhadores do interior dos latifúndios, transformando-os em bóia-frias, moradores das periferias das cidades da região, principalmente Campos. A introdução de melhorias técnicas parciais na produção, concentradas no preparo da terra e nos tratos culturais, e excluindo, em geral, a colheita, acentua a diferença sazonal de requerimento de mãode-obra, gerando uma massa de assalariados temporários.

Com a modernização da industrialização (Proálcool), aumentam as unidades de produção para satisfazer a voracidade da usina: a cana passa a ser queimada para aumentar a produtividade do corte (triplica a produtividade do trabalho do cortador) e não é mais enfeixada; a mecanização da preparação do solo e do plantio permite um redimensionamento dos talhões, que aumentam bastante; a embarcadeira é introduzida para empilhar a cana e carregá-la até os caminhões, agora maiores, ou para as grandes carretas puxadas por tratores. (RUA, 1998: 21/22).

No caso das relações de produção ocorrem paralelamente dois processos: de um lado, a construção de modernas usinas de produção de açúcar e álcool, elimina os antigos engenhos, representando um forte processo de centralização e concentração do capital; de outro lado, há uma concentração fundiária que resulta da redução do número de fornecedores, uma vez que as usinas impõem padrões de produção que muitos

Em 1971 foi criado o Programa de Racionalização da Agroindústria Açucareira, rebatizado de Programa de Apoio à Agroindústria Açucareira em 1973 e o PRÓ-ÁLCOOL foi criado em 1975. A. este respeito ver NEVES, 1997. 
pequenos fornecedores não conseguem cumprir o que acaba por alijá-los do setor, além da estratégia de buscar ampliar a produção própria, como forma das usinas se protegerem contra a concorrência das demais. ${ }^{8}$

O resultado disto é o avanço da urbanização, uma vez que há expressiva expulsão de trabalhadores do campo e crescente subordinação da agricultura à indústria, dentro do novo modelo de produção implantado na região. Também podemos identificar neste processo a metropolização, uma vez que a atividade deixa de ser controlada pelo antigo capital agrário de base local, pois este passa a ser cada vez mais dependente de recursos externos, além do que, grandes grupos empresariais são atraídos para a atividade, diminuindo substancialmente o poder das classes dominantes locais. Neste sentido, podemos dizer que esta é a área do Rio de Janeiro onde ocorre a articulação agricultura-indústria e a fusão dos capitais agrário e urbano-industrial.

Nas demais regiões do estado, o que vemos ao longo do período 1964/1980 é a intensificação das tendências anteriores, isto é: (1) o crescimento industrial e o esvaziamento do campo no Vale do Paraíba; (2) o avanço da especulação imobiliária, via loteamentos populares na região da Baixada da Guanabara; (3) a expansão do turismo, mas também da produção de hortigranjeiros na região Serrana; (4) o esvaziamento populacional crescente do Noroeste.

Neste sentido, é interessante notar que a região Noroeste deixa de seguir a trajetória que vinha copiando da região do Vale do Paraíba, aprofundando seu esvaziamento, ao invés de reverter seu processo de desenvolvimento em direção a um processo de industrialização, o que está relacionado a dois fatores: (1) o distanciamento desta do eixo Rio - São Paulo, centro do desenvolvimento industrial do país; (2) o arrefecimento do desenvolvimento industrial brasileiro a partir do fim do milagre, o que de certa forma limitava a possibilidade de criação de novos eixos de desenvolvimento ${ }^{9}$

Portanto, a marca do período, mais ainda que a metropolização, que persiste avançando, é a desruralização, traduzida principalmente pela redução absoluta da população rural do estado, em todas as regiões, mas também num intenso esvaziamento econômico e político do meio rural fluminense. De outro lado, podemos também observar que é neste período que a atual configuração regional, do ponto de vista dos recortes territoriais, definidos pelos órgãos estatais de planejamento, ganha a forma atual. Resta saber se nos períodos subsequientes o conteúdo muda.

\section{ANOS 1980: DESACELERAÇÃO DA DESRURALIZAÇÃO E DA METROPOLIZAÇÃO}

Os anos 1980 representaram uma certa regressão dos processos que dominaram os períodos anteriores, não no sentido de que tenham sido revertidos, mas de que perderam

${ }^{8}$ Ver NEVES, 1997

${ }^{9}$ Ver a este respeito GRABOIS et al., 1998. 
ímpeto de forma significativa. $\mathrm{O}$ ritmo da urbanização estadual sofre expressiva diminuição, assim como se verifica um princípio de desconcentração espacial da produção industrial.

A região Metropolitana ${ }^{11}$ é neste sentido, palco exemplar das transformações e a maior demonstração disto é o fato de esta região ter se convertido na década de 1980 no principal foco de conflitos fundiários no estado. Ao contrário dos anos 1970, quando os conflitos pela posse da terra concentravam-se nas regiões de expansão do turismo, impulsionados pela especulação imobiliária, nos anos 1980 estes voltarão, a exemplo dos anos 1950/60, a se dar basicamente na Baixada Fluminense, porém com um outro conteúdo.

Se nos anos 1950/60 os conflitos eram resultantes da resistência dos trabalhadores rurais frente aos interesses dos especuladores na conversão das terras da região em áreas de expansão do tecido urbano, nos 1980, os conflitos serão resultado da busca de alternativas de sobrevivência por parte dos trabalhadores desempregados e subempregados da periferia da região.

Tal fato, por si só, demonstra a redução do ímpeto dos processos de metropolização e desruralização. De um lado, indica que muitas áreas consideradas nos anos 1960 como de expansão urbana - a ponto de terem sido devolvidas a seus donos ou pretensos donos, após o golpe de 1964, pelos militares - mantiveram-se à margem da urbanização, o que permitiu que diversas áreas que foram palco de conflitos nos anos 1950/60, voltassem a sê-lo nos anos 1980, seja por estarem abandonadas, ou por terem permanecido ocupadas por posseiros, que passaram a exigir a regularização da posse destas. ${ }^{11}$

Por outro lado, a retomada destes conflitos indica também que o processo de metropolização do espaço fluminense dá os primeiros sinais de crise, uma vez que o que até então era um processo unilinear - a afluência de população para a região Metropolitana do Rio de Janeiro - passa a sofrer a partir deste momento uma reversão.

Nas demais regiões, não tende a haver substancial mudança das tendências delineadas nos anos 1970, exceção feita à região Norte, uma das poucas regiões do estado, onde o peso do capital agrário dinâmico ainda era expressivo. Esta acentua radicalmente os processos de desruralização e metropolização que vinham se desenvolvendo lentamente, transformando a dinâmica regional.

Tal mudança está diretamente ligada ao desenvolvimento da exploração do petróleo na região. A enorme riqueza geológica, no que tange a este estratégico e rentável produ-

\footnotetext{
${ }^{10}$ Cabe aqui um esclarecimento: até então, estávamos utilizando a denominação Baixada da Guanabara para designar a região no entorno da cidade do Rio de Janeiro. A partir deste momento passaremos a adotar a denominação «Região Metropolitana», o que está relacionado com o enorme processo de expansão da urbanização em curso no estado que fez com que os limites da conurbação diretamente vinculada à cidade do Rio de Janeiro extrapolasse os limites da Baixada da Guanabara, estendendose hoje até municípios como Mangaratiba, no Litoral Sul e Itaboraí e Rio Bonito, nas Baixadas Litorâneas.

${ }^{11}$ Ver MEDEIROS et al., 1999.
} 
to, contribuiu para o questionamento de projetos seculares de organização do espaço regional. Esta atividade, além de se tornar a mais importante economicamente, reforçando o papel das atividades urbanas em relação às rurais, resultou numa redefinição das relações interregionais, assim como a industrialização do Vale do Paraíba operara na década de 1940 naquela região.

As diferentes mesorregiões do Estado, em sua disparidade de condições, têm passado por diversas transformações socioespaciais. As alterações na configuração territorial dos municípios têm sido fruto de movimentos emancipatórios que, no caso do Norte Fluminense, estão atreladas principalmente à exploração do petróleo da Bacia de Campos, no litoral. Esta atividade reverte capitais para as prefeituras por meio de pagamento de impostos (royalties). A participação do petróleo na economia dos municípios do Norte Fluminense foi fato novo para uma região em que a formação socioespacial pretérita esteve sempre atrelada quase unicamente à tradicional economia canavieira. (MARAFON e BARBOSA, 2002: p. 83).

Com a transformação da cidade de Macaé na base fundamental de operação da Petrobrás na região, a cidade de Campos, até então o único centro regional de importância, passa a sofrer concorrência direta daquela que passa a nuclear uma série de áreas até então diretamente dependentes de Campos.

Macaé representa um interessante exemplo de município onde as transformações socioeconômicas (atreladas à exploração do petróleo) resultaram em reconfiguração territorial (com o desmembramento dos antigos distritos de Quissamã e Carapebus). Após as emancipações, portanto, Macaé perdeu as grandes áreas que possuía, dedicadas ao plantio e beneficiamento da cana-de-açúcar, não podendo mais ser incluído na tradicionalmente denominada "Zona Canavieira". Vale destacar também que a cidade de Macaé vem crescendo muito rapidamente nas últimas duas décadas, passando a apresentar funções mais diversificadas e a exercer uma maior centralidade. (MARAFON e BARBOSA, 2002: p. 85).

Assim, as transformações em curso na região nos permitem especular inclusive sobre o futuro de sua unidade, uma vez que parece haver uma diferenciação crescente entre os projetos de ordenamento territorial, no que se refere às elites campistas e macaeenses, mas também aos movimentos sociais. Discutiremos isto adiante.

O conjunto das transformações verificadas no espaço agrário fluminense nos últimos anos produz um quadro geral onde o que sobressai é a crise, como pode ser observado nas tabelas 5 e 6 abaixo, que demonstram a redução do número de estabelecimentos, da área agrícola, da produção e do emprego no setor. Os números são tão eloquientes que superam os problemas derivados da mudança de metodologia entre os dois censos, para efeito de comparação. 
Tabela 5 - Uso da terra no estado Rio de Janeiro - 1985/1996

\begin{tabular}{lrrr}
\hline \multicolumn{1}{c}{ Categorias } & \multicolumn{1}{c}{1985} & \multicolumn{1}{c}{1996} & Percentual de Variação (\%) \\
\hline Número de Estabelecimentos & 91.280 & 53.680 & $-41,19$ \\
Área dos Estabelecimentos (ha) & 3.264 .149 & 2.416 .305 & $-25,97$ \\
Pastagens Naturais (ha) & 1.437 .879 & 901.030 & $-37,34$ \\
Matas Naturais (ha) & 463.183 & 323.105 & $-30,24$ \\
Terras Inaproveitáveis (ha) & 207.412 & 107.463 & $-48,19$ \\
Área Produtiva (ha) & 1.155 .675 & 1.084 .707 & $-6,14$ \\
Lavoura (ha) & 624.699 & 337.241 & $-46,02$ \\
Pastagens Plantadas (ha) & 319.227 & 644.093 & $-101,77$ \\
Área em Descanso (ha) & 39.663 & 25.881 & $-34,75$ \\
Área Produtiva Não Utilizada (ha) & 113.720 & 39.180 & $-65,55$ \\
\hline
\end{tabular}

Fonte: Censos Agropecuários de 1985 e 1996, IBGE.

Tabela 6 - Produção, área colhida e rendimento das principais lavouras, segundo os Censos Agropecuários - Rio de Janeiro - 1985/1996

\begin{tabular}{|c|c|c|c|c|c|c|c|c|c|}
\hline \multirow[t]{2}{*}{ Lavouras } & \multicolumn{2}{|c|}{ Produção (t) } & \multicolumn{4}{|c|}{ Área colhida (ha) } & \multicolumn{3}{|c|}{ Rendimento (kg/ha) } \\
\hline & 1985 & $1995 / 6$ & $\%(85 / 96)$ & 1985 & $1995 / 6$ & $\%(85 / 96)$ & 1985 & $1995 / 6$ & $\%(85 / 96)$ \\
\hline Arroz em casca & 85.200 & 17.248 & $-79,76$ & 41.715 & 10.548 & $-74,71$ & 2.042 & 1.635 & $-19,93$ \\
\hline Cana-de-açucar & 8.030 .833 & 5.709 .830 & $-28,90$ & 183.220 & 136.693 & $-25,39$ & 43.832 & 41.771 & $-4,70$ \\
\hline Feijão em grão & 9.184 & 4.060 & $-49,85$ & 18.526 & 11.515 & $-37,84$ & 496 & 400 & $-19,35$ \\
\hline Mandioca & 128.011 & 40.465 & $-68,39$ & 17.771 & 6.197 & $-65,13$ & 7.203 & 6.530 & $-9,34$ \\
\hline Milho & 75.385 & 33.651 & $-55,36$ & 58.635 & 23.741 & $-59,51$ & 1.286 & 1.393 & 8,32 \\
\hline Tomate & 83.248 & 99.695 & $-19,76$ & 4.513 & 5.819 & 28,94 & 18.446 & 17.133 & $-7,12$ \\
\hline Café em coco & 17.282 & 9.398 & $-45,62$ & 16.657 & 12.102 & $-27,35$ & 1.037 & 777 & $-25,07$ \\
\hline Banana* & 28.058 & 8.028 .000 & $-71,39$ & 31.779 & 7.069 & $-77,76$ & 883 & 1.136 & 28,65 \\
\hline Laranja** & 1.863 .017 & 252.882 & $-86,43$ & 29.723 & 6.511 & $-78,09$ & 62.679 & 38.839 & $-38,04$ \\
\hline
\end{tabular}

Fonte: Censo Agropecuário 1995/6, IBGE.

* Produção em Mil Cachos e Rendimentos em Cachos por Hectares

** Produção em Mil Frutos e Rendimentos em Frutos por Hectares

\section{DESMETROPOLIZAÇÃO E RE-RURALIZAÇÃO: NOVAS TENDÊNCIAS DE ORDENAMENTO TERRITORIAL NO RIO DE JANEIRO?}

Se traçar um perfil da geografia do Rio de Janeiro no início do século XX foi relativamente simples, o trajeto percorrido por este texto mostra o quanto esta tarefa é hoje complexa, dadas as múltiplas transformações verificadas no período e a crescente diversificação de projetos de ordenamento territorial, seja do ponto de vista do capital, seja dos trabalhadores. Obviamente - dada a história brasileira do período - os projetos de ordenamento do território da burguesia prevaleceram, embora com alguns impor- 
tantes revezes, expressos por exemplo, na multiplicação de assentamentos rurais ${ }^{12}$, assim com no reconhecimento do direito dos descendentes de indígenas à terra e também de descendentes de escravos, para ficar nas questões que dizem respeito ao assunto que nos interessa mais diretamente que é a organização do espaço agrário.

O mapa atual do estado nos mostra a existência, ao lado de tendência dominantes claras e consolidadas, de importantes disputas em torno do ordenamento territorial. Tentaremos mapear aqui as principais tendências e as disputas em curso.

As mudanças na dinâmica capitalista de acumulação, com a passagem do padrão fordista para o pós-fordista ${ }^{13}$ contribui para o avanço da desmetropolização do espaço fluminense, embora esta seja ainda incipiente, não sendo possível identificar mais que alguns indícios, como as recentes decisões de empresas de porte de se instalar em municípios do interior do estado, como foi o caso da Volkswagen, que decidiu pela instalação de sua mais moderna fábrica de ônibus e caminhões em Porto Real, antigo distrito de Resende.

Observe-se que o novo padrão não produz transformações radicais do ponto de vista da localização, pois um de seus pré-requisitos é a existência de uma infra-estrutura de comunicações e transporte de boa qualidade, condição para a flexibilidade da produção, baseada em fluxos acelerados de produtos e informações. Portanto, as empresas buscam áreas menos saturadas que os grandes centros metropolitanos, mas não necessariamente novas áreas industriais.

Entretanto, se do ponto de vista industrial, isto é, da esfera da produção, vemos uma certa desmetropolização, do ponto de vista da esfera da circulação esta é reforçada, como indica a ampliação da atividade turística nas diversas regiões do estado, a qual está fortemente vinculada ao deslocamento sazonal da população da Região Metropolitana. Aliás, a mobilidade territorial é hoje a norma, num mundo comandado pelas finanças: mobilidade das indústrias, do comércio, do trabalho, da natureza, das pessoas em busca do lazer.

Assim, não podemos falar exatamente da existência de um processo de desmetropolização, mas de um contraditório processo em que numa esfera, a da produção, esta se verifica, ao mesmo tempo em que noutra esfera, a da circulação, esta se intensifica.

\footnotetext{
${ }^{12}$ Apesar das inúmeras controvérsias dos dados do ITERJ e do INCRA, levantamos a existência de 70 assentamentos no Rio de Janeiro, com um total de 8.609 famílias. Além disso, uma série de áreas foram objetos de outros tipos de intervenção fundiária, como veremos adiante. Ver Tabela 1 do Anexo 1 .

${ }^{13}$ As transformações recentes no capitalismo têm sido objeto de profundas controvérsias que vão desde a consideração acerca do caráter das mudanças em curso até a denominação destes processos. Utilizamos aqui a denominação «pós-fordista», na medida em que nossa preocupação no momento é exclusivamente relativa às transformações no âmbito da produção industrial. Para maior esclarecimentos em relação à referida polêmica, ver entre outros KUMAR, 1997.
} 
Neste sentido, Rua (2002) aponta a existência de cinco grandes eixos de urbanização no Estado: (1) Rio-Macaé, marcado pela expansão do turismo e da segunda residência, mas também da indústria do petróleo e da reativação da pesca; (2) Rio-Macacu, via Manilha, marcado pela expansão de loteamentos urbanos, atividades rurais nãoagrícolas e indústrias; (3) Rio-Parati, marcado pela expansão do turismo, comércio, serviços e da industrialização; (4) eixo do «topo da serra» que vai de Rio Claro até Cantagalo, marcado pela expansão do turismo, da industrialização e de atividades rurais não-agrícolas, mas também da agroindustrialização (verifica-se ainda um sub-eixo que se estende de Petrópolis a Três Rios apoiado na indústria e no turismo); (5) do Médio Paraíba, entre Resende e Três Rios, marcado fundamentalmente pelo avanço da indústria de base, mas também da multiplicação de hotéis-fazenda.

Os dados da Tabela 7, abaixo, reforçam tal análise, pois observa-se que são exatamente as regiões cortadas por tais eixos as mais urbanizadas.

Tabela 7 - População residente, por situação de domicílio, segundo as regiões de governo Rio de Janeiro - 1985/1996

\begin{tabular}{|c|c|c|c|c|}
\hline \multirow{2}{*}{ Regiões de Governo } & \multicolumn{3}{|c|}{ População residente } & \multirow{2}{*}{$\frac{\text { Taxa de }}{\text { Urbanização (\%) }}$} \\
\hline & Total & Urbana & Rural & \\
\hline Estado & 14367083 & 13798096 & 568987 & 96,04 \\
\hline Região Metropolitana & 10872768 & 10792513 & 80255 & 99,26 \\
\hline Região Noroeste Fluminense & 297512 & 253534 & 61978 & 79,18 \\
\hline Região Norte Fluminense & 696988 & 593025 & 103963 & 85,08 \\
\hline Região Serrana & 751428 & 625495 & 125933 & 83,24 \\
\hline Região das Baixadas Litorâneas & 560298 & 481546 & 78752 & 85,94 \\
\hline Região do Médio Paraíba & 784813 & 730124 & 54689 & 93,03 \\
\hline Região Centro-Sul Fluminense & 254575 & 211572 & 43002 & 83,11 \\
\hline Região da Baía da Ilha Grande & 148701 & 128286 & 20415 & 86,27 \\
\hline
\end{tabular}

Fonte: IBGE, Censo Demográfico 2000.

Embora concordemos com Rua (2002) quanto aos eixos de urbanização apontados, discordamos da inclusão das atividades não-agrícolas entre as evidências da existência dos mesmos. A nosso ver, não se trata de um processo de urbanização e conseqüientemente de desruralização, mas de um contraditório processo de re-ruralização, no qual há uma revalorização do espaço rural - seja como área de moradia, seja como locus de uma produção em moldes diferenciados do padrão típico da revolução verde -, que não significa uma volta ao antigo rural, mas a produção de um novo rural e a revitalização demográfica, econômica, política e cultural deste, transformado pelo próprio processo de urbanização e, no caso, do Rio de Janeiro, de metropolização.

Esta revalorização do rural se expressa no avanço do ecoturismo, na expansão de atividades de lazer em áreas rurais, como pesque-pagues e hotéis-fazenda, e na conversão 
de antigas áreas agrícolas em área de veraneio e segunda moradia para as classes média e alta da região Metropolitana. Expressa-se também no desenvolvimento de formas de produção agrícola alternativas que incorporam crescentemente a dimensão ambiental, respeitando a diversidade dos ecossistemas, em oposição ao modelo homogeneizador da revolução verde.

Em termos regionais, esta tendência de revalorização do rural é mais expressiva no Litoral Sul e na região Serrana, áreas onde o maior grau de preservação da Mata Atlântica favorece o desenvolvimento do ecoturismo, mas também se verifica no Vale do Paraíba, onde desenvolve-se crescentemente um turismo histórico que revaloriza as antigas fazendas de café, o que dá novo alento à região de Valença e Vassouras, que, como vimos, perdera importância dentro da região, frente ao maior desenvolvimento industrial do eixo da Via Dutra.

Também na região Serrana temos a maior presença da agricultura ecológica, o que está ligado ao papel que esta nunca deixou de desempenhar de produtora de hortigranjeiros para o abastecimento metropolitano, apesar do avanço recente do turismo sobre antigas áreas agrícolas, porém, não exclusivamente, uma vez que também no Litoral Sul e até na região Metropolitana essas experiências se multiplicam.

A região Serrana é por sua vez também o palco principal do desenvolvimento de um outro processo que é a multiplicação da pluriatividade entre os pequenos agricultores. Premidos pela crise, expostos cada vez mais à urbanização e pressionados pela valorização crescente de suas terras pela expansão do turismo, muitas famílias de pequenos agricultores da região transformam-se em pluriativas, combinando a renda obtida na própria propriedade com outras atividades desenvolvidas fora desta (principalmente ligados à prestação de serviços e ao turismo). ${ }^{14}$

Por seu turno, o Noroeste segue sua saga de esvaziamento, embora em alguns municípios venha se expandindo uma pequena agricultura voltada para o abastecimento da região Metropolitana, em parte em função da crescente perda de espaço desta atividade na região Serrana e em parte pela melhoria das condições de acesso à região, com a abertura e melhoria das rodovias que a ligam ao restante do estado.

No caso da região Norte, o que se observa hoje é uma tentativa das antigas elites canavieiras de buscar alternativas à crise do setor, de modo a fazer frente à ofensiva do MST na região. Na esteira desta crise, o MST organizou uma série de ocupações que redundaram na criação de vários assentamentos na região, sendo um de grande porte, resultante da ocupação de uma das maiores e mais tradicionais usinas de cana de Campos, a São João, hoje transformada no assentamento Zumbi dos Palmares.

Como resposta a esta afronta direta a seu tradicional poderio, a oligarquia canavieira busca, diante das dificuldades de retomada do Pró-Álcool, alternativas produtivas que preservem seu poder na região, como o pólo de fruticultura irrigada, projeto formulado pela Federação das Indústrias do Rio de Janeiro (Firjan), que tem como um de seus

${ }^{14}$ Para uma análise mais detalhada ver TEIXEIRA, 1998. 
vice-presidentes um dos herdeiros de uma das poucas usinas que ainda não faliram (MEDEIROS et al., 1999).

Entretanto, as características estruturais da região tendem a representar obstáculos ao desenvolvimento de alternativas, mesmo na visão daqueles que defendem a preservação de um importante papel para a atividade canavieira, como se depreende do trecho abaixo:

A crise econômica provocada pela liberação dos preços e pelo fim de uma tradição subvencionista por parte do Estado, no início da década de 90, só veio agravar a situação dos fornecedores de cana e das usinas do Norte Fluminense. Apesar deste quadro extremamente desfavorável, a economia canavieira na região em questão deve continuar a ser alvo de atenção, por sua ainda expressiva fonte de ocupação da mão-de-obra rural, sem a qual não restariam opções de trabalho para grande parte da população. A estrutura fundiária concentrada e a falta de opções para o desenvolvimento socioeconômico, historicamente fizeram do Norte e do Noroeste Fluminense áreas de êxodo rural e expulsão de população para outras regiões do Estado do Rio ou mesmo para outras partes do país. (MARAFON e BARBOSA, 2002:84).

A isto, junta-se a crescente importância da cidade de Macaé na região, como visto anteriormente, o que acentua as possibilidades de fragmentação da regional.

Assim, mais uma vez, percebe-se que a Região Norte é um dos principais pólos de disputa em torno de um projeto de ordenamento territorial hoje no Rio de Janeiro, e uma das únicas onde um projeto popular busca se afirmar, uma vez que os demais processos em andamento não afetam diretamente os projetos do capital, pelo contrário, adequam-se ao novo padrão de acumulação vigente.

Este é o caso do ecoturismo, um mercado em rápida expansão que tem se tornado cada vez mais um grande negócio, embora representasse originalmente uma crítica à destruição ambiental produzida pelo capital em sua voracidade na apropriação da natureza. O mesmo pode ser dito do turismo histórico que revaloriza o Vale do Paraíba, recuperando inclusive uma outrora arrasada e decadente oligarquia agrária cafeeira. Obviamente, não é esta oligarquia que se beneficia do turismo histórico, uma vez que a maioria das grandes fazendas foi comprada por especuladores e grandes empresários residentes na capital, mas representa a revalorização de seu modo de vida.

No que se refere à expansão da agricultura alternativa, podemos dizer que é um processo contraditório: de um lado, o mercado destes produtos ainda é restrito basicamente a uma parcela da elite metropolitana, cujas preocupações ecológicas sustentam esta produção, de custo mais elevado que o dos produtos tradicionais; de outro, na medida em que esta atividade não se presta à extensividade, exige grande volume de mão-de-obra e gera retornos mais lentos, embora mais sustentáveis, tende a se basear 
fundamentalmente na agricultura familiar e em unidades de pequeno e médio porte, o que permite vislumbrar uma mudança no perfil da estrutura agrária do estado.

Assim, o que podemos verificar hoje é que a maior parte dos projetos de ordenamento territorial, nas diversas regiões do estado, representa a continuidade, embora em novas bases, do domínio do capital sobre o espaço fluminense, agora hegemonizado pela esfera da circulação, pelo capital financeiro, ainda que articulado com outros segmentos, e valorizando novas atividades, dentre as quais destacam-se o lazer e o turismo.

\section{BIBLIOGRAFIA}

ALENTEJANO, Paulo R. R. 1997. Reforma Agrária e Pluriatividade no Rio de Janeiro: repensando a dicotomia rural-urbano nos assentamentos rurais. Dissertação de Mestrado. Rio de Janeiro: CPDA/UFRRJ, 1997.

2003. Reforma agrária, território e desenvolvimento no Rio de Janeiro.

Tese de Doutorado. Rio de Janeiro: CPDA/UFRRJ, 2003.

BRITO, Maristela \& INNOCENCIO, Ney R. 1988. Organização do espaço agrário no Estado do Rio de Janeiro: Revista Brasileira de Geografia. IBGE. Ano 50, n. 3. CIDE. 1998.

Anuário estatístico do Estado do Rio de Janeiro. Rio de Janeiro: Fundação CIDE. 2001. Anuário estatístico do Estado do Rio de Janeiro. Rio de Janeiro: Fundação CIDE. CIDE.

2002. Anuário estatístico do Estado do Rio de Janeiro. Rio de Janeiro: Fundação

FIBGE. 1970, 1985 e 1995/96. Censos Agropecuários. Rio de Janeiro: FIBGE. 1970, 1980, 1991 e 2000. Censos Demográficos. Rio de Janeiro: FIBGE.

GALVÃO, Maria do Carmo Corrêa. 1986. «Rio de Janeiro - contradições e ajustes de um espaço desigual.» Revista Rio de Janeiro. v.1 n 3. Niterói: mai-ago.

GRABOIS, José, CÉZAR, L. H. S., SANTOS, C. P., GONÇALVES, D. M., FABRÍCIO, S. M., FICO, B. V., QUINTANILHA, L. B. M. \& MACHADO, T. M. R. 1998. «O papel da pequena produção na organização de um espaço periférico: o caso do Noroeste Fluminense.» In CARNEIRO, M. J., GIULIANI, G. M., MEDEIROS, L. S. \& RIBEIRO, A. M. M. (orgs.) Campo aberto: o rural no estado do Rio de Janeiro. Rio de Janeiro: Contra Capa Livraria.

KUMAR, Krishan. 1997. Da sociedade pós-industrial à pós-moderna: novas teorias sobre o mundo contemporâneo. Rio de Janeiro: Jorge Zahar Editores.

MARAFON, Gláucio J. e BARBOSA, Pedro P. B. C. 2002. «O papel do complexo agroindustrial sucro-alcooleiro nas transformações sócioespaciais do Norte Fluminense.» In: MARAFON, Gláucio J. e RIBEIRO, Marta F. (orgs.). Estudos de Geografia Fluminense. Rio de Janeiro: Livraria e Editora Infobook Ltda.

MEDEIROS, L. S., LEITE, S. L. BENEDETTI, A., CABANILHA, I. e 
ALENTEJANO, P. R. R. 1999. «Luta por terra e assentamentos rurais no Rio de Janeiro.» In: MEDEIROS, L. S. \& LEITE, S. A formação dos assentamentos rurais no Brasil: processos sociais e políticas públicas. Porto Alegre/Rio de Janeiro: Ed. da Universidade/ UFRGS/ CPDA/ UFRRJ.

NEVES, Delma P. 1997. Assentamento rural: reforma agrária em migalhas. Niterói: EDUFF.

RUA, João. «Implicações territoriais do processo de modernização no município de Quissamã (RJ).» GeoUERJ. nº 4. jul-dez.

RUA, João. 2002. «Urbanidades e novas ruralidades no Estado do Rio de Janeiro: algumas considerações teóricas.» In: MARAFON, Gláucio J. e RIBEIRO, Marta F. (orgs.). Estudos de Geografia Fluminense. Rio de Janeiro: Livraria e Editora Infobook Ltda..

SANTOS, Milton e SILVEIRA, Maria L. 2001. O Brasil: território e sociedade no início do século XXI. Rio de Janeiro: Record.

TEIXEIRA, Vanessa L. 1998. Pluriatividade e agricultura familiar na Região Serrana do Estado do Rio de Janeiro. Dissertação de Mestrado. Rio de Janeiro: UFRRJ. 